\title{
Aquatic pollution from anthropogenic discharges modulates gene expression in liver of rainbow trout (Oncorhynchus mykiss)
}

\author{
Guillermo E. Valenzuela-Nieto ${ }^{\text {a\#}}$, Carlos Leal ${ }^{\mathrm{b}, \mathrm{c}}$, Julia Schwaiger ${ }^{\mathrm{d}}$, Hermann Ferling ${ }^{\mathrm{d}}$, \\ Luis Vargas-Chacoff ${ }^{c, e^{*}}$, Gudrun Kause $^{\mathrm{a}^{*}}$
}

\begin{abstract}
With the aim to characterise the biological impact of anthropogenic discharge in a river, gene expression in fish was evaluated as a biomarker for mixture effects of potential toxic compounds in the aquatic environment. Adult male rainbow trout (Oncorhynchus mykiss) were used as monitoring organisms. Within the German experimental set up, trout were exposed actively for 28 days in biologically purified sewage as well as in river water up- and downstream of the sewage treatment plant (STP) effluent. In a different approach, wild trout were captured in southern Chile near anthropogenic discharges. Fish were taken from river Maullin receiving sewage from a settlement and from river Pescado influenced by effluents from a fish farm. In vivo effects were assessed by RT-qPCR analyses of biomarker gene expression, vitellogenin $(v g)$, metallothionein $(m t)$ and cytochrome 1A (cyplA) in liver samples with primers amplifying specific sequences previously confirmed by cloning and sequencing. The modulation of expression of marker genes involved in metal stress, reproduction and detoxifying systems in the liver of male rainbow trout revealed organismal response to anthropogenic contamination in two different study areas, such as Chile and Germany, thereby indicating a potential risk on the aquatic ecosystems.

Key words: anthropogenic discharges in river, gene expression, liver biomarkers, environmental exposure, Oncorhynchus mykiss.
\end{abstract}

\section{INTRODUCTION}

Currently, ecotoxicology faces a huge challenge in evaluating toxicity and how mixtures of chemical compounds can affect wild life in the aquatic environment (Holmstrup et al 2010, Kumar and Denslow 2017). Evaluation of biomarkers in exposed organisms can enhance characterisation of biological impact from aquatic pollution (Connon et al 2012). Endocrine disruptors (EDs) are natural or manmade substances that are able to interfere with the endocrine system and therefore represent a significant threat for aquatic organisms and human health (Rappaport and Smith 2010, Kortenkamp 2017). Many genes responsive to xenobiotic compounds have been reported in in vitro assays, but an effect of a particular chemical in vitro may not necessarily be predictive of its in vivo effects due to factors such as biodegradation and metabolism (Tyler et al 1998, Wilson et al 2016). However, analyses of robust molecular biomarkers in fish should facilitate diagnosis of

Received: 10.11 .2020

Accepted: 26.01.2021.

anstituto Bioquímica y Microbiología, Facultad Ciencias, Universidad Austral de Chile, Valdivia, Chile.

${ }^{b}$ Escuela de Graduados, Programa de Doctorado en Ciencias de la Acuicultura, Universidad Austral de Chile, Puerto Montt, Chile.

'Instituto Ciencias Marinas y Limnologicas, Facultad Ciencias, Universidad Austral de Chile, Valdivia, Chile.

${ }^{\mathrm{d} B a v a r i a n}$ Environment Agency, Unit Aquatic Ecotoxicology, Microbial Ecology, Wielenbach, Germany.

${ }^{e}$ Centro Fondap de Investigación de Altas Latitudes (IDEAL), Universidad Austral de Chile, Valdivia, Chile.

\#These authors contributed equally to the study

*Corresponding authors: Dr. Luis Vargas-Chacoff; luis.vargas@uach.cl; Dr. Gudrun Kausel, gkausel@uach.cl sublethal adverse effects in organisms within the aquatic environment.

Besides heavy metals and dioxin-like compounds, estrogenic compounds are among the most studied contaminants because they are suspected to affect male fertility (Marlatt et al 2016). The latter include natural estrogen steroids, e.g. 17 $\beta$-estradiol, phytoestrogens, and mycoestrogens, synthetic estrogens such as ethinylestradiol, as well as various industrial compounds and organic contaminants (Kagi 1993). On the other hand, the induction of vitellogenin (VG) synthesis in male fish has been widely used as a biomarker to detect estrogenic effects of xenoestrogens in the field (Schwaiger and Negele 1998). Vitellogenin (VG) is a precursor of the egg yolk protein which is synthesised physiologically in the liver of female fish during sexual maturation (Copeland et al 1986). The synthesis of VG is initiated by binding of an estrogen to a highly specific estrogen receptor in the hepatocytes (Mommsen and Walsh 1988, Benninghoff and Williams 2008). Males also produce VG under the influence of estrogenic compounds (Mommsen and Walsh 1988). An overexpression of VG has been observed in male carp as a consequence of exposure to estrogenic compounds (Valenzuela et al 2015) and is considered as part of a feminisation process in male fish (Hamilton et al 2014).

Another marker to evaluate the toxic effects of xenobiotics in the aquatic environment is Cytochrome-P450 (cyp1) (Buhler and Wang-Buhler 1998, Zhou et al 2010, Burkina et al 2017). This system plays a role in xenobiotic metabolism and some endogenous compound metabolism, such as steroids, fatty acids and prostaglandins (Arukwe 2002). Also cypl is upregulated in response to dioxins and polycyclic aromatic hydrocarbons (PAH) (Buhler and Wang-Buhler 1998, Zhou et al 2010, Burkina et al 2017). 
Metallothioneins (MT) belong to a family of cysteinerich low molecular weight proteins capable of binding both physiologically important natural and xenobiotic heavy metals. MT play a key role in homeostasis because they are involved in detoxification of potentially toxic metals (Chen et al 2007). MT overexpression was observed in response to heavy metals in mollusks and fish (Roesijadi 1994). Synthesis of MT is mainly induced by exposure to metals and to a less degree by hormones, cytokines and organic contaminants (Kagi 1993).

Chemical-analytical investigations are, in many cases, not suitable for identifying individual compounds because of the broad spectrum of anthropogenic substances and their often-discontinuous emission into the aquatic environment. While chemical analyses usually represent a snapshot, biomarker responses integrate a specific load over an extended time period. Furthermore, a biomarker response does not only point to a specific pollution of a water body, but also to the fact that the substances have been taken up and have led to an effect in the intact organism. Therefore, the use of specific biomarkers in fish represents a valuable tool for detecting aquatic pollution. In the present study two different experiments were carried out comparatively. The first one represents an active monitoring experiment using rainbow trout (Oncorhynchus mykiss) as test organisms. This study was performed at a sewage treatment plant (STP) and the respective receiving river in Bavaria, Germany. The location was chosen because at low flow rates during heat periods, the dilution ratio between waste water and river water can be 1:1. In such worst-case situations, a relatively high chemical load could be assumed. The second experiment was carried out in Patagonia, Chile. Within the frame of a passive monitoring program, adult male rainbow trout were captured in Maullin and Pescado river, located in Llanquihue Province, Región de Los Lagos, Chile. Fish were captured upstream and downstream of an anthropogenic emission including sewage treatment plant as well as fish farm effluents. The aim of this study was to reveal the biological effects of anthropogenic pollution by evaluating the transcriptional level of metallothionein $(\mathrm{mt})$, vitellogenin $(\mathrm{vg})$, and cytochrome 1A (cypla) genes as molecular endpoints in the liver of male rainbow trout, reflecting organismal response in two different areas of the world.

\section{MATERIAL AND METHODS}

\section{SAMPLE COLLECTION}

The experiment in Germany was performed at a sewage treatment plant (STP) located in a small village in Bavaria, Germany. The STP has a catchment area of approximately 35,000 inhabitants. The investigations were carried out within the framework of an official water monitoring program of the federal state of Bavaria. In the exposure experiment, 4-years old adult male rainbow trout
(Oncorhynchus mykiss) reared in unpolluted spring water under disease-controlled conditions, with body weight of $1441.44 \mathrm{~g} \pm 212.68$ and body length of $49.62 \mathrm{~cm} \pm 2.39$, were obtained from the breeding stock of the Bavarian Environment Agency and were used as test organisms. In each experimental setup, 20 fish were exposed in fish tanks (bypass exposure) to water of a small river upstream (US) and downstream (DS) of a sewage treatment plant (STP), as well as directly to the biologically purified sewage (D) for 28 days. A control group (C) was maintained in a tank receiving uncontaminated spring water. In all 4 experimental set ups, during the entire test period, the chemical-physical water parameters $\mathrm{O}^{2}, \mathrm{pH}$, temperature $\mathrm{T}^{\circ} \mathrm{C}$ and conductivity were measured continuously by using an online analytical system (IQ Sensor Net System 2020; WTW, Germany). Furthermore, the flow rates of the STP-effluent and the effluent receiving river were determined by means of a flow meter (Flowtronic, Typ Flo-Dar, Belgium) during the whole experiment. Figure 1 shows the bypass exposure tanks which were equipped with samplers and the online measuring systems.

The animal experiments were approved by the competent authority in the government of Upper Bavaria and were carried out according to the requirements of the German animal welfare legislation.

After the exposure period, fish were anaesthetised in MS222 (Tricaine, Pharmaq Ltd. 10g/100L) and subsequently killed by decapitation. After necropsy of fish, liver samples of 7 (US), 8 (DS), 7 (D), and 6 (C) individuals were removed and immediately submerged in Chomczynski solution for RNA preparation (Chomczynski and Sacchi 1987).

In the Chilean Patagonia, adult male rainbow trout were captured in the Maullin and Pescado rivers, both located in the Llanquihue Province, Región de Los Lagos. The fish were captured $1000 \mathrm{~m}$ upstream (US) and within $20 \mathrm{~m}$ downstream (DS) of discharge site. Conductivity was measured with Multiparameter Meter Model HI9829 (Hanna). Sampling sites were chosen because of accessibility in the field with the electric fishing device (Pottier et al 2019). Electric fishing preferable captures small fish expected to exhibit low mobility (Habera et al 2010). The source of contamination in the Maullin river was a sewage treatment plant discharge. Three male trout were captured upstream (US) and downstream (DS), respectively. In the Pescado river, which receives the effluent of a fish farm, six male trout were captured at each sampling site, upstream (US) and downstream (DS). Individual rainbow trouts were captured using electrofishing equipment (EFKO, model FEG 1000, $1 \mathrm{KW}, 150-600 \mathrm{~V})$. Fish were netted and submitted to lethal doses of 2-phenoxyethanol ( $1 \mathrm{~mL} / \mathrm{L})$ and euthanised by spinal section before tissues were removed. The liver was extracted and immediately submerged in RNAlater solution (Qiagen). The performed experiments complied with the Guidelines of the Comisión Nacional de Ciencia y Tecnología de Chile (CONICYT) and the Universidad Austral de Chile for the use of laboratory animals. 


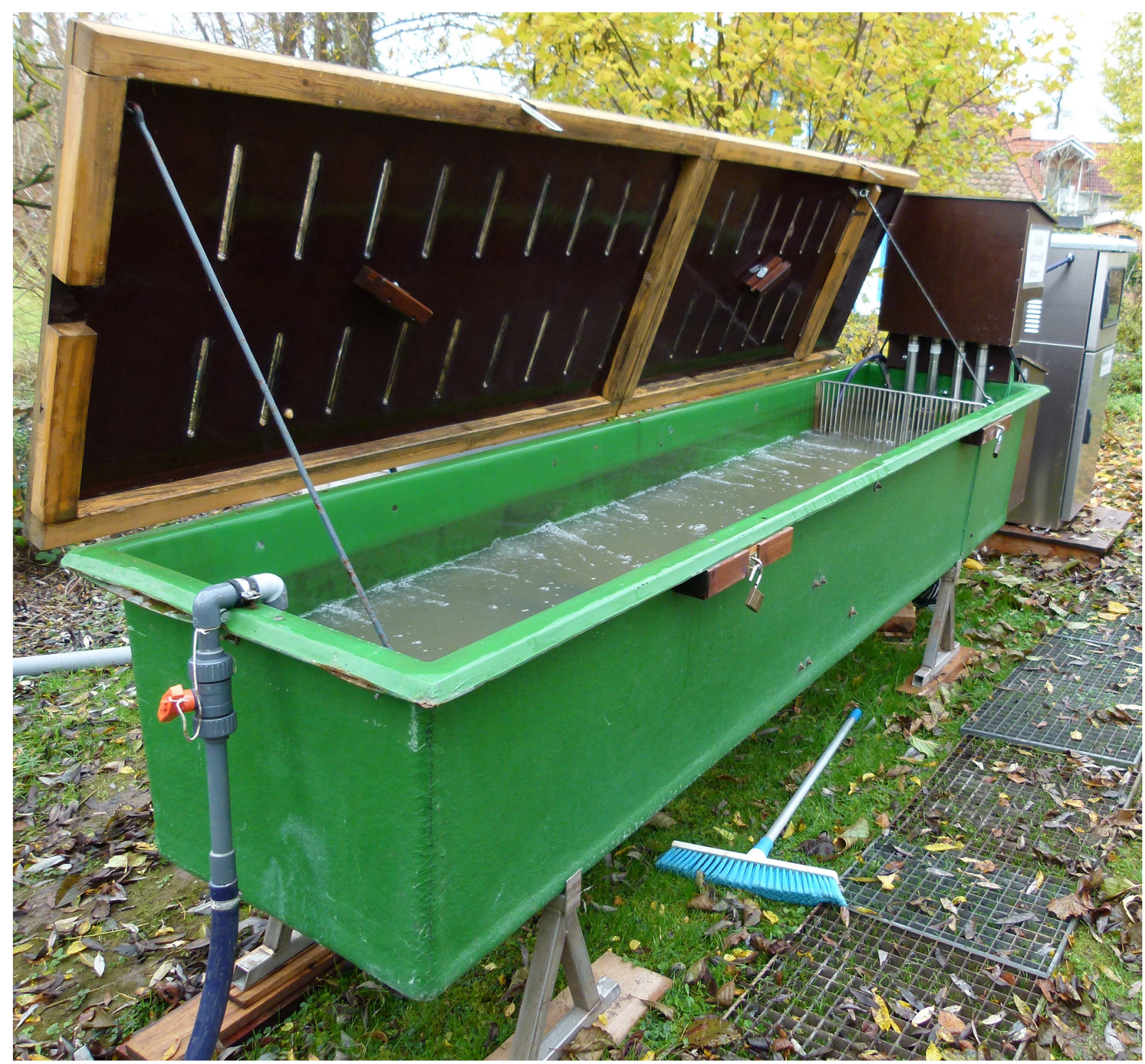

Figure 1. Fish tanks (bypass exposure) equipped with an online analytical system (IQ Sensor Net System 2020; WTW, Weilheim, Germany).

\section{RT-qPCR ANALYSES}

Total RNA was extracted with Chomczynski solution for RNA according to the suppliers' instructions (Winkler Ltd.). From total RNA cDNA was prepared with oligo-dT and M-MLV reverse transcriptase (Promega) according to standard procedures (Sambrook et al 1989). Specific primer pairs for rainbow trout genes were designed with Primer3 program for quantitative real-time PCR (qPCR) on cDNA template for metallothionein $m t$, vitellogenin $v g$ and cytochrome 1A cyp 1a (table 1). First, specificity of all amplicons was verified by cloning and sequencing. Next, all samples were processed in parallel. qPCR assay was conducted using Brilliant RII SYBRR Green, qPCR Master
Mix (Agilent Technologies) according to the suppliers' instructions in a Mx3000 Real-Time Thermocycler. In a 40 cycles PCR reaction each cycle consisted in $20 \mathrm{~s}$ at $94{ }^{\circ} \mathrm{C}, 15 \mathrm{~s}$ at $55^{\circ} \mathrm{C}$ and $15 \mathrm{~s}$ at $72{ }^{\circ} \mathrm{C}$, followed by final heating to $95^{\circ} \mathrm{C}$ revealing melting curves of unique amplification products. All analyses were performed in duplicate. The expression level of each gene was normalised to elongation factor 1a (efla) expression as reference gene with exon-spanning primers to control for genomic DNA contamination since no DNAse treatment of total RNA was included. RT-qPCR assays were analysed with $2^{-\Delta \Delta C t}$ method (Livak and Schmittgen 2001) via MxPro software (Stratagene) and expressed as Relative Quantity to Normalizer (Pfaffl 2001). 
Table 1. Oligonucleotides for RT-qPCR analyses in Oncorhynchus mykiss.

\begin{tabular}{lccc}
\hline Gene & acc number* & Oligonucleotides & Amplicon (bp) \\
\hline Elongation factor $1 \alpha(e f 1 \alpha)$ & NM001124339 & $\begin{array}{c}\text { omEF 1a s ctgaaggccggtatgatcgt } \\
\text { omEF 1a a acattgtcaccaggcatggc } \\
\text { omMTa s atcctgcaagtgctccaac }\end{array}$ & 110 \\
Metallothionein a $(m t a)$ & M18103.1 & $\begin{array}{c}\text { omMTa a acaaagctatgctcaagatgg } \\
\text { omVG s gggaagatgccaaggcagag }\end{array}$ & omVG a agcggcttcatgaggtagt \\
Vitellogenin $(v g)$ & X92804.1 & omCyp 1a s agtgatgagttgggcaggt & 176 \\
Cytochrome 1A $($ cyp 1A) & AF015660.1 & omCyp 1a a tcacggatgttgtccttgtc & 178 \\
\hline
\end{tabular}

*acc number: GenBank accession number.

\section{STATISTICAL ANALYSES}

The determined mRNA levels were presented as relative quantity to normalizer (dR) for three genes independently ( $m t, v g$, cyp $1 \mathrm{a})$. The data from caged rainbow trout $(\mathrm{C}, \mathrm{n}=6$; US, $\mathrm{n}=7$; D, n=7; DS, n=8) were analysed with One-way analysis of variance (ANOVA). For the data analyses of fish captured in Chile, from Maullin river (US, $n=3 ; D S$, $\mathrm{n}=3$ ) and Pescado river (US, $n=6 ; \mathrm{DS}, \mathrm{n}=6$ ), the Unpaired Student's T-test was applied. Differences were considered significant at $P<0.05$.

\section{RESULTS}

\section{CHEMICAL-PHYSICAL PARAMETERS AND FLOW RATES} DURING THE EXPOSURE EXPERIMENTS

In figure 2 the chemical-physical data during the experiment are given. The continuous analysis of $\mathrm{pH}$ in the three test groups and the control approach revealed only slight deviations varying from 7.6 to 8.2. The water temperature varied depending on the trial site. The highest temperature, which was measured directly in the STP-effluent was in the range of $12.5^{\circ} \mathrm{C}$. The temperature in the river upstream of the effluent was $7.4{ }^{\circ} \mathrm{C}$, whereas downstream the mean temperature was determined to be $8.8^{\circ} \mathrm{C}$. The temperature of the spring water used to expose control fish was $10.3{ }^{\circ} \mathrm{C}$. The conductivity varied between 1255.3 $\mu \mathrm{s} / \mathrm{cm}$ in the STP-effluent and $722.4 \mu \mathrm{s} / \mathrm{cm}$ in the control water. In the river upstream of the STP-effluent discharge, the mean conductivity was $824 \mu \mathrm{s} / \mathrm{cm}$, and downstream it was $975.4 \mu \mathrm{s} / \mathrm{cm}$. The mean oxygen concentration in the control water was $9.3 \mathrm{mg} / \mathrm{l}$, in the river upstream of the STP-effluent it was $10.5 \mathrm{mg} / \mathrm{l}$ and downstream it was 10 $\mathrm{mg} / \mathrm{l}$. The lowest oxygen concentration of $8.2 \mathrm{mg} / \mathrm{l}$ was analysed directly in the STP-effluent.

The continuous measurement of the flow rate in the STP-effluent revealed, with the exception of an increase in the first and third week of the experiment, a usually very stable flow rate (figure 3 ). The flow rate in the river downstream was in general higher than in the STP-effluent and displayed also 2 peaks in the first and third week accordingly.

\section{EFFECTS IN MALE RAINBOW TROUT EXPOSED TO STP EFFLUENTS AND CORRESPONDING RIVER WATER}

In Bavaria, Germany, expression analyses of biomarker genes from caged male rainbow trout (figure 4) revealed that there was no significant difference in expression of mta gene between C, US, D and DS groups. No significant difference in the expression levels of $v g$ gene was observed between control individuals and the other three groups. A significant decrease in expression of $v g$ was detected in the DS group compared to the D group. Due to the fact that expression levels of $v g$ in the US and D group revealed a high variability, no significant difference was shown between these two groups. A significant increase in the expression of cypla gene was observed in the US, D and DS groups in comparison to the control group C. Furthermore, the expression level of cypla gene was significantly lower in the DS group than in the US and D groups.

\section{DISCHARGE EFFECT ON MALE RAINBOW TROUT CAPTURED FROM MAULLIN AND PESCADO RIVER}

In the Patagonian rivers (table 2), the sampling season was spring (november) for Maullin river which receives municipal wastewater, water temperature was similar US $\left(14^{\circ} \mathrm{C}\right)$ and $\mathrm{DS}\left(16^{\circ} \mathrm{C}\right)$, conductivity was $52 \mu \mathrm{S} / \mathrm{cm}$ US and $35 \%$ higher at DS $(80 \mu \mathrm{S} / \mathrm{cm})$. A total of ten fish were captured, five at each site. From Maullin river the fish sampled from US had a mean size $25.2 \mathrm{~cm} \pm 10.4$, DS $21.2 \mathrm{~cm} \pm 6.3$. In Río Pescado, receiving effluents of a fish farm, during the winter (August) sampling season, the temperature at US $\left(7^{\circ} \mathrm{C}\right)$ was five degrees lower than on DS $\left(12^{\circ} \mathrm{C}\right)$ and conductivity varied from $66 \mu \mathrm{S} / \mathrm{cm}$ US to $84 \mu \mathrm{S} / \mathrm{cm}$ DS, an increase of $21 \%$. Six fishes were captured at each site. From Pescado river captured fish mean size was US $9.3 \mathrm{~cm} \pm 0.6$, and DS $13.4 \mathrm{~cm} \pm 3.8$.

In the Maullin river (figure 5), no differences were observed in the expression of mta between the two 


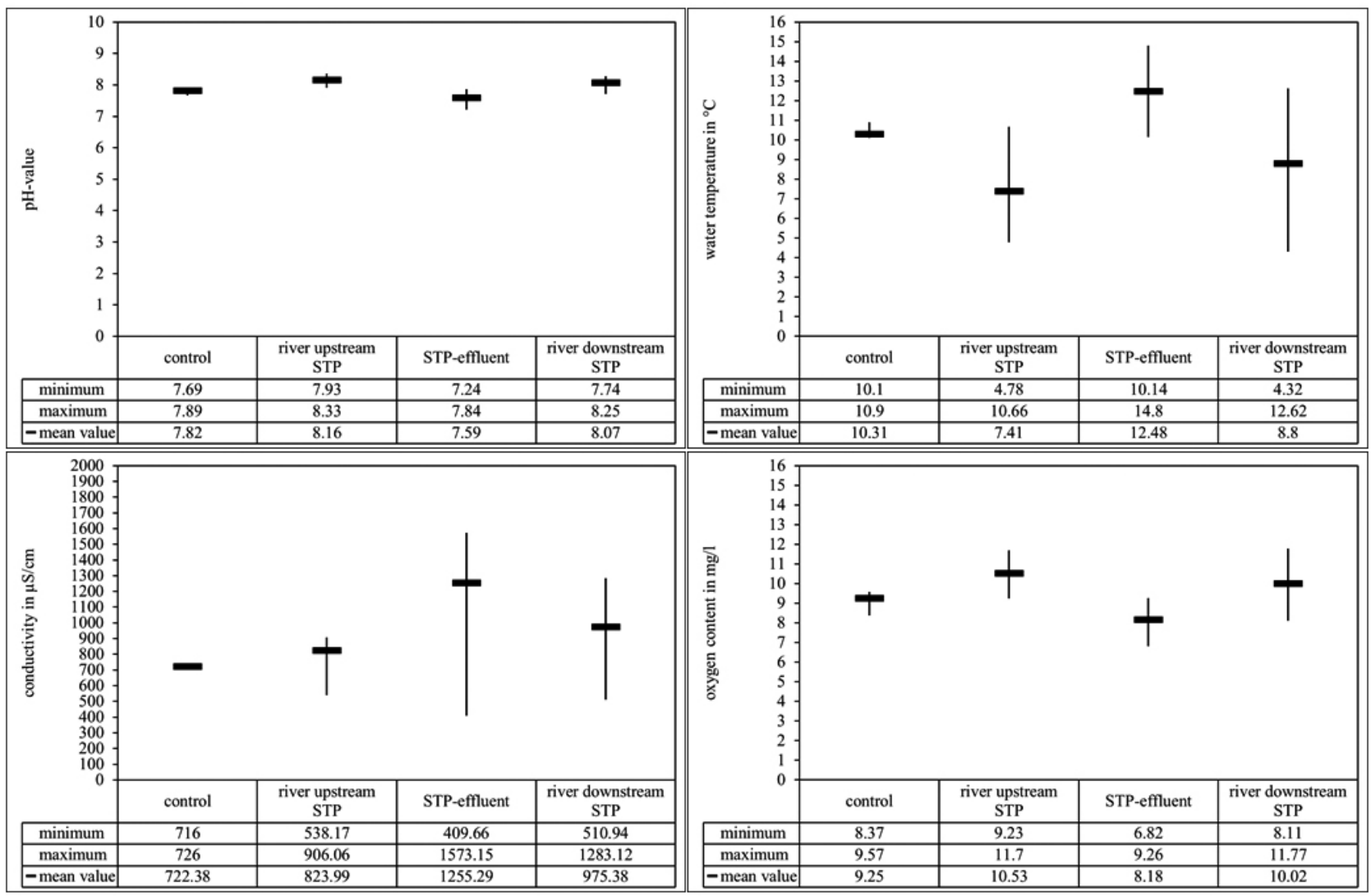

Figure 2. Online chemical-physical data during the 28-days experiment $\left(\mathrm{pH}\right.$, temperature $\mathrm{T}^{\circ} \mathrm{C}$, conductivity and $\left.\mathrm{O}^{2}\right)$ of biologically purified STP-effluent, river water upstream and downstream of STP-effluents and Control spring water (mean \pm standard deviation).

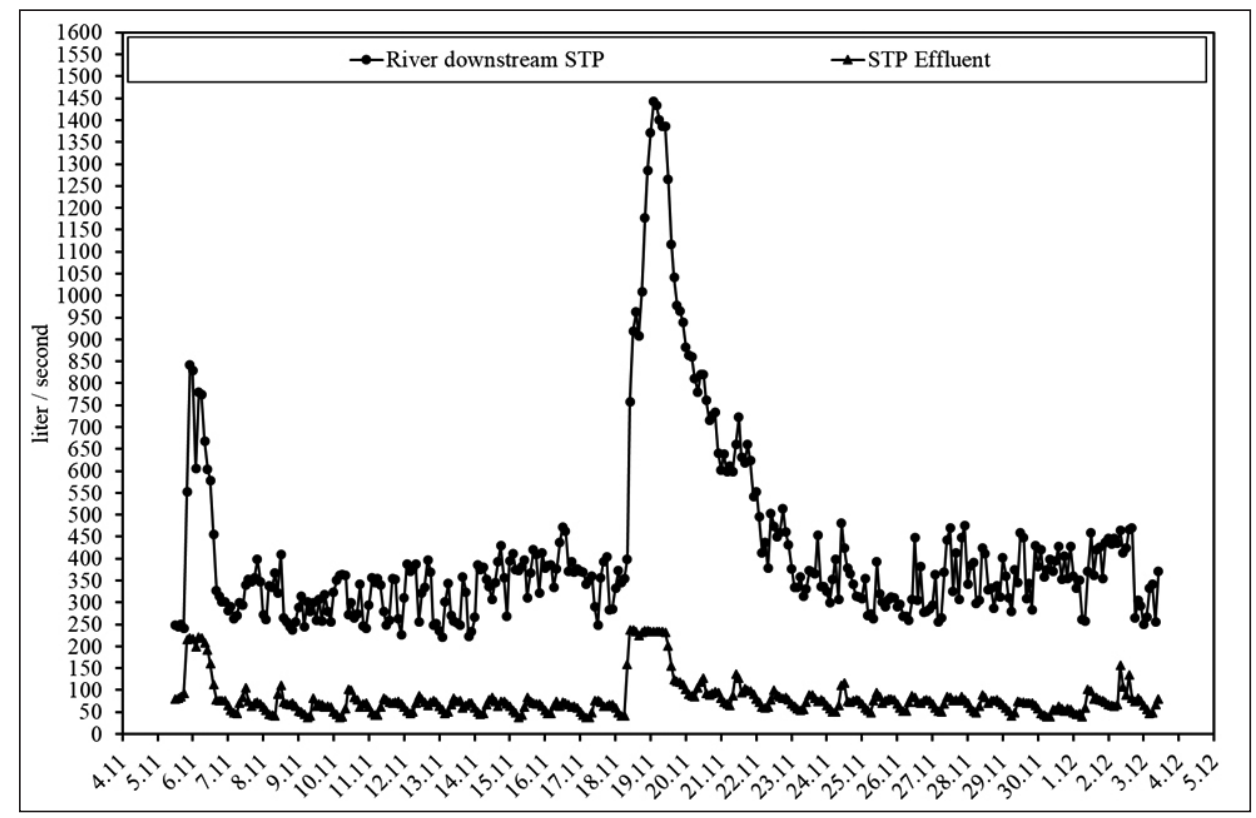

Figure 3. Daily average flow rates of the STP-effluent and the effluent receiving river during the 28-days exposure period. 
Table 2. Biophysical data of $O$. mykiss caught in Patagonians rivers.

\begin{tabular}{lcc}
\hline & Maullin River & Pescado River \\
\hline Sampling season & spring (November) & winter (august) \\
Location & US DS & US DS \\
Water temperature $\left({ }^{\circ} \mathrm{C}\right)$ & 1416 & 712 \\
Water conductivity $(\mu \mathrm{S} / \mathrm{cm})$ & 5280 & 6684 \\
O. mykiss number $(\mathrm{n})$ & 55 & 66 \\
Size $(\mathrm{cm})$ & $25.2 \pm 10.421 .2 \pm 6.3$ & $9.3 \pm 0.613 .4 \pm 3.8$ \\
\hline
\end{tabular}

A

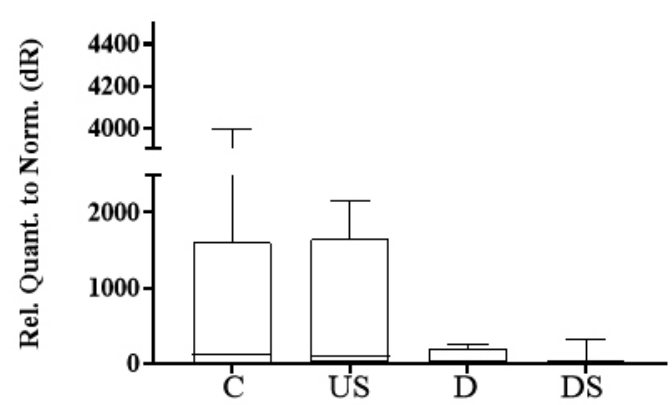

B

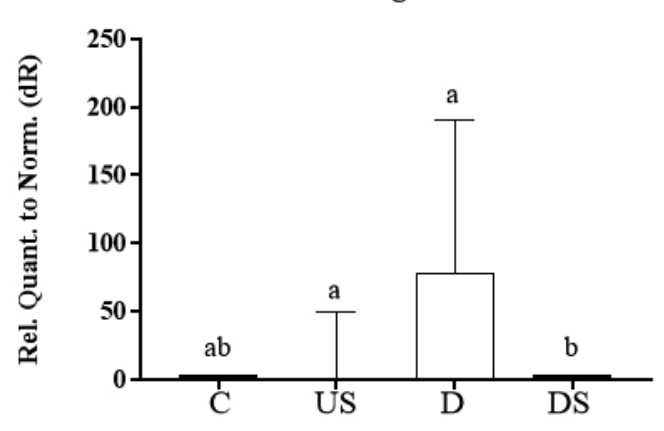

$\mathrm{C}$

cyp1a

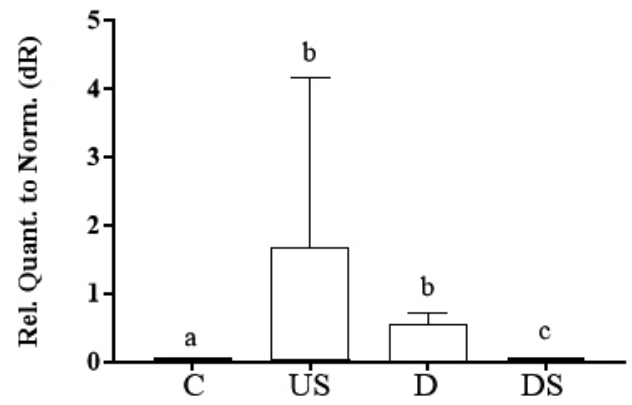

Figure 4. Sewage discharge effect on expression of marker genes in liver of caged male rainbow trout (Bavaria, Germany). mRNA levels of (A) metallothionein A ( $m t a)$, (B) vitellogenin $(\mathrm{vg})$ and (C) cytochrome 1A (cypla) in liver were measured using RT-qPCR and represented as relative quantity to normaliszer gene $(\mathrm{dR})$. Analyses were performed in duplicate and all data were normalised for efla gene expression. Graphs depict gene expression data of C (control) n=6, US (upstream sewage discharge) $n=7$, D (at sewage discharge site) $n=7$ and DS (downstream sewage discharge) $n=8$. The box plot shows the median (middle line), the $75^{\text {th }}$ and $25^{\text {th }}$ percentiles and the maximum and minimum values (top and bottom of the whiskers). $P<0.05$ was considered statistically significant difference, indicated by different letters.

experimental groups. With regard to the expression of $v g$ gene, at least one of the male trout captured downstream the discharge site showed a clear increase, whereas in trout captured further upstream very consistent low expression levels were detected. In fish captured downstream of the discharge, the level of expression of cypla significantly decreased in comparison to fish captured upstream of the discharge site.

In the Pescado river (figure 6), a comparison of mta expression in male rainbow trout captured up- and downstream of effluents from a fish farm revealed no significant differences between fish from the two sites, except for one individual from downstream that exhibited clearly upregulated $m t a$ expression. No clear differences in $v g$ expression levels were established between fish captured upstream or downstream of a discharge site. Furthermore, in trout captured downstream the discharge site the expression of cypla tended to increase compared to individuals sampled upstream of the fish farm emission. 
A

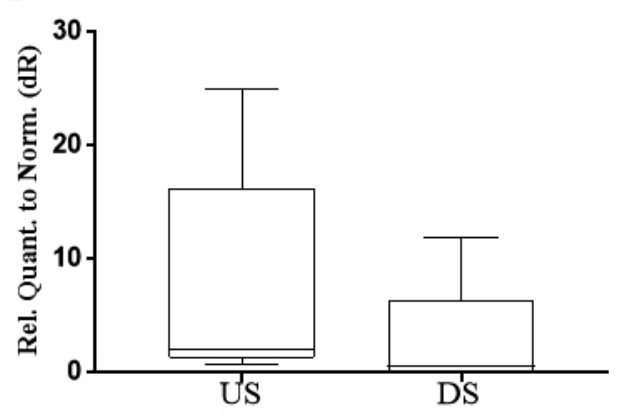

B

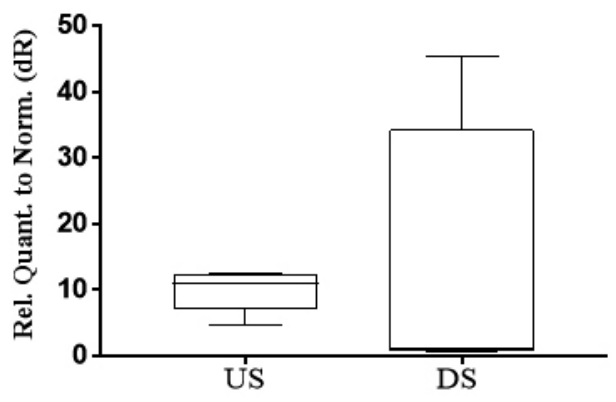

$\mathrm{C}$

cyp1a

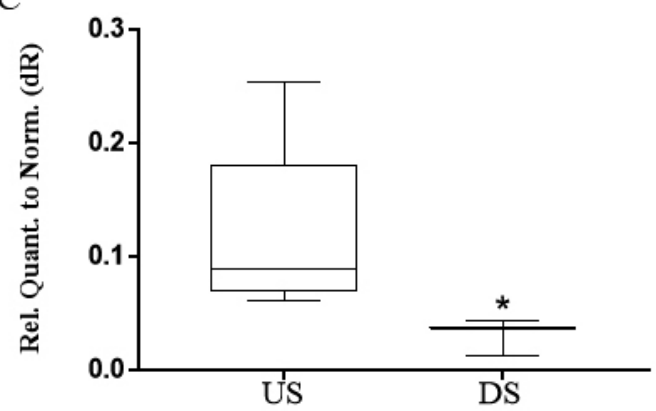

Figure 5. Discharge effect on expression of genes in liver of male rainbow trout captured in Maullin river. At Maullin river fish were captured US and DS of STP effluents. mRNA levels of (A) $m t a$, (B) $v g$ and (C) cypla in liver were measured using RT-qPCR. Analyses were performed in duplicate and all data were normalised for efla gene expression. Graphs depict relative quantity to Normalizer gene $(\mathrm{dR})$ from individual adult male trout captured upstream of the discharge zone (US, $n=3$ ) and downstream discharge zone (DS, $\mathrm{n}=3$ ). The box plot shows the median (middle line), the $75^{\text {th }}$ and $25^{\text {th }}$ percentiles and the maximum and minimum values (top and bottom of the whiskers). $P<0.05$ was considered statistically significant difference, indicated by different letters.

\section{DISCUSSION}

The present study was performed in order to implement a set of specific biomarkers on the transcriptional level of metallothionein, vitellogenin and cytochrome 1A. To prove the suitability of biomarkers, rainbow trout deriving from an exposure experiment in Bavaria, Germany, as well as individuals caught in two remote rivers in Patagonia, Chile, were examined comparatively.

Molecular endpoints in the liver of rainbow trout were used as biomarkers to assess the impact of anthropogenic discharge containing pollutant mixtures in one location in Bavaria, southern Germany, and in two rivers in southern Chile. Rainbow trout served as the model fish because of their wide distribution and sensitivity towards environmental pollution (Marlatt et al 2016, Martyniuk et al 2020).

Although farmed rainbow trout were used as test organisms which ensured a homogeneous test collective, in the caged fish from the experiments conducted in Germany a variability of the gene responses was obvious. The reason for the higher variability of expression levels observed predominantly in upstream compared to downstream samples is not clear. The variability of biomarker response could not be related to migration of experimental fish because trout were held in tanks and exposure took place via bypass. Possibly, the exposure to the effluent might pose constraint on the underlying variability in the real-world situation (Tyler et al 1998). Since $m t a$ was not affected, heavy metal stress seems to be unlikely (Ricketts et al 2015, Valenzuela et al 2015). In previous work, we observed a clear increase in the expression of $m t$ in response to zinc in carp liver, with no concomitant significant change of $v g$ expression. In a parallel experiment, a significant increase of $v g$ expression in response to $17 \beta$-estradiol was not accompanied by changes in $m t$ expression. This leads to the suggestion that specific stimuli elicit specific physiological responses, activating either the heavy metal response pathway or the estrogen receptor pathway, thereby validating the use of $m t$ and $v g$ as specific biomarker genes (Valenzuela et al 2015). Due to the fact that $v g$ expression did not increase significantly in male fish exposed to STP-effluents at D compared to control, but was at least higher compared to fish exposed downstream of the effluents, estrogenic contaminants cannot be excluded. The continuous measurement of flow rates in our study revealed throughout the exposure period significantly higher flow rates in the river downstream of the discharge compared to the STP-effluent itself. 
A

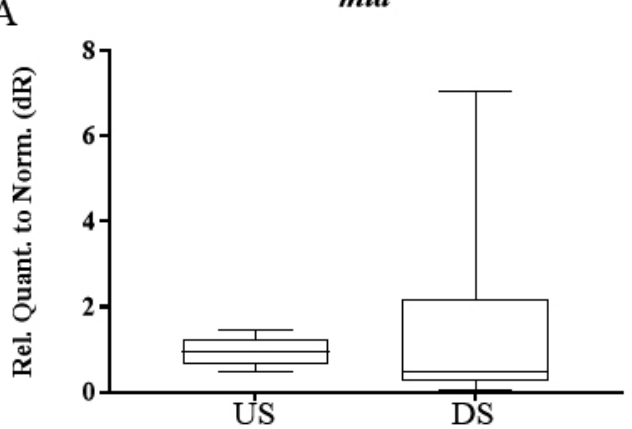

B

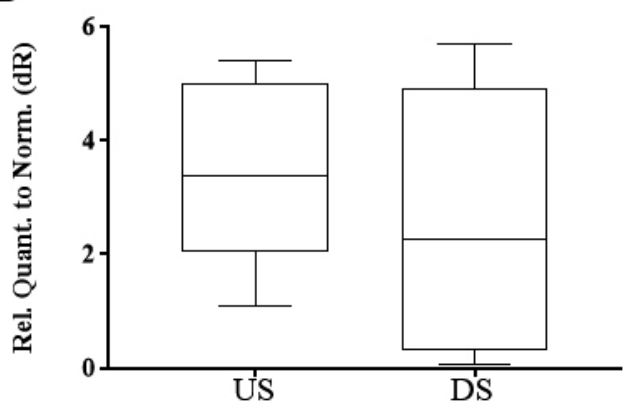

$\mathrm{C}$

cyp1a

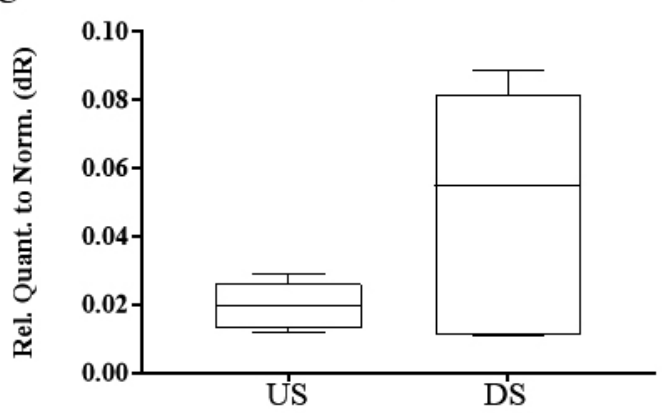

Figure 6. Discharge effect on expression of genes in liver of male rainbow trout captured in Pescado river. At Pescado river fish were captured US and DS of aquaculture effluent. mRNA levels of (A) $m t a,(\mathrm{~B}) v g$ and (C) cypla in liver were measured using RT-qPCR. Analyses were performed in duplicate and all data were normalized for $e f l a$ gene expression. Graphs depict Relative Quantity to Normalizer gene $(\mathrm{dR})$ from individual adult male trout upstream (US, n=6) and downstream of a discharge zone (DS, n=6). The box plot shows the median (middle line), the $75^{\text {th }}$ and $25^{\text {th }}$ percentiles and the maximum and minimum values (top and bottom of the whiskers). Considering $P<0.05$, no statistically significant difference was found.

As described elsewhere (Osachoff et al 2016), it can be assumed that, within the exposure period, dilution in the river might lead to concentrations under the detection level. The significant higher transcript level of cyplA in samples from US and D as compared to controls implies an impact of compounds which are able to interact with the arylhydrogen receptor pathway and might reflect a dose dependent stress response (Zhou et al 2010, Ings et al 2011). The decrease of expression levels in fish exposed downstream of the discharge site might again be a consequence of higher dilution in the river.

At two remote field sites in southern Chile, for the firsttime biomarker gene expression profiles in rainbow trout were used as representatives of physiological parameters to enhance insight into the effects of pollutants on wild trout from punctual release of sewage in Maullin river and discharge of aquaculture effluents in Pescado river. In the present study in Patagonia, fish were captured in the field in proximity of the discharge site, therefore, in contrast to the study in Germany with caged fish, mobility between sampling sites of free living individuals cannot be excluded. However, several studies have revealed that trout often remain stationary for long periods of time. A study in a New Zealand river that was performed over 72 days with recordings every 2 to 3 days, reported that half of the radio tagged wild rainbow trouts (40 individuals) were found to remain in their home area (Dedual and Jowett 1999). Specially, small individuals seem to move very little, as shown by radiotracking of hatchery raised trout of different size released in a Californian river (Cocherell et al 2010). Over a period of 9 weeks with weekly revision, small sized rainbow trout mainly remained in one location, with movements of less than about $500 \mathrm{~m}$ (Cocherell et al 2010). In accordance with these observations, mobility between US and DS seems very unlikely in the small rainbow trout sampled in the proximity of anthropogenic discharges in Patagonian rivers.

As far as we know, the data from the samplings at Maullin and Pescado rivers contribute biological base line information for wild trout in these areas, which might be important for further spatio-temporal monitoring schemes (Tattam et al 2016).

At Maullin river, apart from one exception, low levels of $m t a$, and variable $v g$ levels indicate little or no effect on genes regulated via heavy metal or estrogenic response elements present in $m t a$ or $v g$ promoter regions, respectively (Kagi 1993, Zhou et al 2010). However, the nearly 10 times higher $v g$ transcripts in one individual captured downstream of discharge site compared to all other samples might indicate triggering of a response 
to estrogenic compounds in male trout, consistent with other in vivo and in vitro observations (Benninghoff and Williams 2008, Gagné et al 2013, Osachoff et al 2016). In this respect, it is known from other monitoring programs in Chile that e.g. pulp and paper production effluents lead to increased $v g$ expression in in situ exposed rainbow trout (Chiang et al 2015).

At Pescado river, which receives effluents from a fish farm, a higher number of samples revealed a more consistent picture. Discharges from aquaculture facilities might include organic load such as faeces and unconsumed food as well as xenobiotics such as antibiotics and disinfectants (Nimptsch et al 2015). With regard to $m t a$ and $v g$ expression no clear differences were found between fish captured upstream or downstream of discharge site. However, a nearly four times higher cyp $1 A$ transcript level in 50 percent of the fish caught at the discharge site might indicate a mobilisation of the xenobiotic-metabolising system (Burkina et al 2017). This could possibly be related to a contamination with toxic compounds, which are usually applied ectopically to limit propagation of highly infectious diseases impacting trout farms in southern Chile (Cárcamo et al 2017).

In the present study, three biomarkers indicative for adverse effects of contaminants on fish were evaluated and should be further strengthened by extending the panel of marker genes in future studies (Martyniuk et al 2020).

In recent years, the increasing concern on environmental impacts of anthropogenic contaminants in former pristine Patagonian rivers prompted toxicological studies in order to generate data on the presence and concentration of potential toxic substances (Alonso et al 2017). The importance of such data has been shown in other reports such as a study conducted as a whole-lake experiment in Canada, which demonstrated that chronic exposure to mixtures or even low levels of estrogen may exert dramatic effects on wild fish populations (Kidd et al 2007). Molecular biomarkers do not only play a pivotal role for the determination of water quality and detection of detrimental effects in complex mixtures (Triebskorn et al 2002, He et al 2017). Molecular biomarkers also can greatly support efficient monitoring of ameliorating protective measures within the frame of regular surveillance, as has been shown by means of decreasing $v g$ concentrations in rainbow trout, indicating a reduction of estrogenic activity in STP-effluents and connected surface water as a consequence of advanced wastewater treatment (Henneberg and Triebskorn 2015).

In conclusion, the main outcome of this study is that different profiles of marker gene expression detected by RT-qPCR analyses in rainbow trout are suitable tools to indicate exposure to estrogenic or other xenobiotic compounds in the field. They can be used as a specific early warning system of a potential risk for the aquatic ecosystem. These data substantiate the importance of early alert biomarkers for biomonitoring and natural resource management such as Patagonian rivers.

\section{ACKNOWLEDGEMENTS}

This work was partially supported by National Funds for Scientific and Technological Development in Chile, CONICYT 21130511 (GV); FONDECYT 1160877, FONDAP IDEAL 15150003 (LV-C). This research received funding from the European Union's Horizon 2020 research and innovation program under the Marie Sklodowska-Curie grant agreement No. 722634 (GK). Conflict of interest: none.

\section{REFERENCES}

Alonso Á, Figueroa R, Castro-Díez P. 2017. Pollution assessment of the Biobío River (Chile): Prioritization of substances of concern under an ecotoxicological approach. Environ Manage 59, 856-869.

Arukwe A. 2002. Complementary DNA cloning, sequence analysis and differential organ expression of $\beta$-naphthoflavone-inducible cytochrome P4501A in Atlantic salmon (Salmo salar). Comp Biochem Physiol - C Toxicol Pharmacol 133, 613-624.

Benninghoff A, Williams D. 2008. Identification of a transcriptional fingerprint of estrogen exposure in rainbow trout liver. Toxicol Sci 101, 65-80.

Buhler D, Wang-Buhler J.L. 1998. Rainbow trout cytochrome P450s: purification, molecular aspects, metabolic activity, induction and role in environmental monitoring. Comp Biochem Physiol - C Pharmacol Toxicol Endocrinol 121, 107-137.

Burkina V, Rasmussen M, Pilipenko N, Zamaratskaia G. 2017. Comparison of xenobiotic-metabolising human, porcine, rodent, and piscine cytochrome P450. Toxicology 375, 10-27.

Cárcamo JG, Aguilar M, Carreño C, Vera T, Arias-Darraz L, et al. 2017. Consecutive emamectin benzoate and deltamethrin treatments affect the expressions and activities of detoxification enzymes in the rainbow trout (Oncorhynchus mykiss). Comp Biochem Physiol Part - C Toxicol Pharmacol 191, 129-137.

Chen W, Christopher-John J, Lin C, Chang C. 2007. Expression pattern of metallothionein, MTF-1 nuclear translocation, and its DNA-binding activity in zebrafish (Danio rerio) induced by zinc and cadmium. Environ Toxicol Chem 26, 110-117.

Chiang G, Barra R, Díaz-Jaramillo M, Rivas M, Bahamonde P, et al. 2015. Estrogenicity and intersex in juvenile rainbow trout (Oncorhynchus mykiss) exposed to Pine/Eucalyptus pulp and paper production effluent in Chile. Aqua Toxicol 164, 126-134.

Cocherell SA, Jones GJ, Miranda JB, Cocherell DE, Cech JJ, et al. 2010. Distribution and movement of domestic rainbow trout, Oncorhynchus mykiss, during pulsed flows in the South Fork American River, California. Environ Biol Fish 89, 105-116.

Connon R, D’Abronzo L, Hostetter N, Javidmehr A, Roby D, et al. 2012. Transcription profiling in environmental diagnostics: Health assessments in Columbia River basin steelhead (Oncorhynchus mykiss). Environ Sci Technol 46, 6081-6087.

Copeland P, Sumpter J, Walker T, Croft M. 1986. Vitellogenin levels in male and female rainbow trout (Salmo gairdneri Richardson) at various stages of the reproductive cycle. Comp Biochem Physiol - B Biochem Mol Biol 83, 487-493.

Dedual M, Jowett IG. 1999. Movement of rainbow trout (Oncorhynchus mykiss) during the spawning migration in the Tongariro River, New Zealand. N Z J Mar Freshwater Res 33, 107-117.

Gagné F, Smyth S, André C, Douville M, Gélinas M, et al. 2013. Stressrelated gene expression changes in rainbow trout hepatocytes exposed to various municipal wastewater treatment influents and effluents. Environ Sci Pollut Res 20, 1706-1718.

Habera JW, Kulp MA, Moore SE. 2010. Three-pass depletion sampling accuracy of two electric fields for estimating trout abundance in a low-conductivity stream with limited habitat complexity. $N \mathrm{Am} \mathrm{J}$ Fish Manag 40, 757-766.

Hamilton P, Nicol E, De-Bastos E. Williams R, Sumpter J, et al. 2014. Populations of a cyprinid fish are self-sustaining despite widespread feminization of males. BMC Biol 12, 1. 
He Y, Folkerts E, Zhang Y, Martin J, Alessi D, et al. 2017. Effects on biotransformation, oxidative stress, and endocrine disruption in rainbow trout (Oncorhynchus mykiss) exposed to hydraulic fracturing flowback and produced water. Environ Sci Technol 51, 940-947.

Henneberg A, Triebskorn R. 2015. Efficiency of advanced wastewater treatment technologies for the reduction of hormonal activity in effluents and connected surface water bodies by means of vitellogenin analyses in rainbow trout (Oncorhynchus mykiss) and brown trout (Salmo trutta f. fario). Environ Sci Eur 27, 1-12.

Holmstrup M, Bindesbøl A, Oostingh G, Duschl A, Scheil V. 2010. Interactions between effects of environmental chemicals and natural stressors: A review. Sci Total Environ 408, 3746-3762.

Ings J, Servos M, Vijayan M. 2011. Exposure to municipal wastewater effluent impacts stress performance in rainbow trout. Aquat Toxicol 103, 85-91.

Kagi J. 1993. Evolution, structure and chemical activity of class I metallothioneins: An overview. In: Suzuki KT, Imura N, Kimura M (eds). Metallothionein III, Biological Roles and Medical Implications. Birkhauser Verlag, Basel, Switzerland, Pp 29-55.

Kidd K, Blanchfield P, Mills K, Palace V, Evans J, et al. 2007. Collapse of a fish population after exposure to a synthetic estrogen. Proc Natl Acad Sci USA 104, 8897-8901.

Kortenkamp A. 2017. Endocrine disruptors: The burden of endocrinedisrupting chemicals in the USA. Nat Rev Endocrinol 13, 6-7.

Kumar G, Denslow N. 2017. Gene expression profiling in fish toxicology: A Review. Rev Environ Contam Toxicol 241, 1-38.

Livak K, Schmittgen T. 2001. Analysis of relative gene expression data using real-time quantitative PCR and the $2^{-\Delta \Delta \mathrm{ct}}$ Method. Methods 25, 402-408.

Marlatt V, Sherrard R, Kennedy C, Elphick J, Martyniuk C. 2016. Application of molecular endpoints in early life stage salmonid environmental biomonitoring. Aquat Toxicol 173, 178-191.

Martyniuk CJ, Feswick A, Munkittrick KR, Dreier DA, Denslow ND. 2020. Twenty years of transcriptomics, 17alpha-ethinylestradiol, and fish. Gen Comp Endocrinol 286113325.

Mommsen T, Walsh P. 1988. Vitellogenesis and oocyte assembly. In: Hoar WS, Randall DJ (eds). Fish Physiology.Vol XIA. Academic Press, New York, USA, 347-406.

Nimptsch J, Woelfl S, Osorio S, Valenzuela J, Ebersbach, et al. 2015. Tracing dissolved organic matter (DOM) from land-based aquaculture systems in North Patagonian streams. Sci Total Environ 537, 129-138.
Osachoff H, Brown L, Tirrul L, Van Aggelen G, Brinkman F, et al. 2016. Time course of hepatic gene expression and plasma vitellogenin protein concentrations in estrone-exposed juvenile rainbow trout (Oncorhynchus mykiss). Comp Biochem Physiol - Part D Genomics Proteomics 19, 112-119.

Pfaffl M. 2001. A new mathematical model for relative quantification in real-time RT-PCR. Nucleic Acids Res 29, 2003-2007.

Pottier G, Beaumont WR, Marchand F, Le Bail P-Y, Azam D, et al. 2019. Electrofishing in streams of low water conductivity but high biodiversity value: Challenges, limits and perspectives. Fish Manag Ecol 27, 53-63.

Rappaport S, Smith M. 2010. Environment and disease risks. Science $330,460-461$

Ricketts C, Bates W, Reid S. 2015. The effects of acute waterborne exposure to sublethal concentrations of molybdenum on the stress response in rainbow trout, Oncorhynchus mykiss. PLoS One 10, 1-22.

Roesijadi G. 1994. Metallothionein induction as a measure of response to metal exposure in aquatic animals. Environ Health Perspect 102, 91-95.

Sambrook J, Fritsch E, Maniatis T. 1989. Molecular cloning: A laboratory manual. Cold Spring Harbor Laboratory Press, New York, USA.

Schwaiger J, Negele R. 1998. Plasma vitellogenin - A blood parameter to evaluate exposure of fish to xenoestrogens. Acta Vet Brno 67, 257-264.

Tattam IA, Li HW, Giannico GR, Ruzycki JR. 2016. Seasonal changes in spatial patterns of Oncorhynchus mykiss growth require year-round monitoring. Eco Freshw Fish 26 434-443.

Triebskorn R, Adam S, Casper H, Honnen W, Pawert M. 2002. Biomarkers as diagnostic tools for evaluating effects of unknown past water quality conditions on stream organisms. Ecotoxicology 11, 451-465.

Tyler C, Jobling S, Sumpter J. 1998. Endocrine disruption in wildlife: A critical review of the evidence. Crit Rev Toxicol 28, 319-361.

Valenzuela G, Perez A, Navarro M, Romero A, Figueroa J, et al. 2015. Differential response of two somatolactin genes to zinc or estrogen in pituitary of Cyprinus carpio. Gen Comp Endocrinol 215, 98-105.

Wilson J, Berntsen H, Zimmer K, Verhaegen S, Frizzella C, et al. 2016. Do persistent organic pollutants interact with the stress response? Individual compounds, and their mixtures, interaction with the glucocorticoid receptor. Toxicol Lett 241, 121-132.

Zhou H, Wu H, Liao C, Diao X, Zhen J, et al. 2010. Toxicology mechanism of the persistent organic pollutants (POPs) in fish through AhR pathway. Toxicol Mech Methods 20, 279-286. 